\title{
Comparison of look-locker and MOLLI sequences for T1 mapping in hypertrophic and ischemic cardiomyopathy
}

\author{
Xiaopeng Zhou ${ }^{1,2^{*}}$, Melanie Traughber ${ }^{3}$, Prabhakar Rajiah', Deborah Kwon ${ }^{1}$, Paul Schoenhagen ${ }^{1,2}$, Scott D Flamm¹, \\ Randolph Setser ${ }^{1,2}$
}

From 16th Annual SCMR Scientific Sessions

San Francisco, CA, USA. 31 January - 3 February 2013

\section{Background}

MOLLI gained popularity since it was first described in 2004, appearing to be more reliable to determine myocardial T1 time, but its relationship to LL, particularly in patients with myocardial disease, has not been fully evaluated. The purpose of this study was to compare pre- and post-contrast T1 values obtained from MOLLI and LL in several subject groups.

\section{Methods}

5 control patients $(4 \mathrm{M} / 1 \mathrm{~F}$, age $44 \pm 21$ y) with normal left ventricular (LV) function and no history of heart disease, 5 patients with ICM $(3 \mathrm{M} / 2 \mathrm{~F}, 63 \pm 2 \mathrm{y})$, and 16 patients with HCM $(10 \mathrm{M} / 6 \mathrm{~F}$, age $51 \pm 15 \mathrm{y})$ were recruited into an IRB approved protocol. All subjects were imaged at $1.5 \mathrm{~T}$ (Achieva XR, Philips). T1 mapping was performed using MOLLI and LL at 2 LV short axis levels (basal- and midcavity) before and after contrast agent injection (Magnevist; $0.2 \mathrm{mmol} / \mathrm{kg}$ ). Post gadopentetate dimeglumine (Magnevist; $0.2 \mathrm{mmol} / \mathrm{kg}$ ) injection time was about $15 \mathrm{~min}$ for HCM and ICM patients and was shorter (about $5 \mathrm{~min}$ ) for the controls due to organizational reasons. For each subject, TI measurements were made in 6 ROIs per level.

\section{Results}

Bland-Altman plots for all data combined are shown in Figure 1; trends were identical among the 3 groups when evaluated separately. Pre-contrast T1 values were significantly higher using MOLLI than LL for all 3 groups: controls (MOLLI $983 \pm 48 \mathrm{~ms}$ vs LL $898 \pm 69 \mathrm{~ms}$, $\mathrm{p}<0.001$ ), HCM (MOLLI $1029 \pm 44 \mathrm{~ms}$ vs LL $917 \pm 58 \mathrm{~ms}$, $\mathrm{p}<0.001$ ), and ICM (MOLLI $1083 \pm 136 \mathrm{~ms}$ vs LL 900 $\pm 112 \mathrm{~ms}, \mathrm{p}<0.001$ ).

Post-contrast $\mathrm{T} 1$ values were significantly higher using MOLLI than LL for controls and HCM only: controls (MOLLI $474 \pm 70 \mathrm{~ms}$ vs LL $465 \pm 64 \mathrm{~ms}, \mathrm{p}<0.001$ ), HCM (MOLLI $488 \pm 59 \mathrm{~ms}$ vs LL $474 \pm 54 \mathrm{~ms}, \mathrm{p}<0.001$ ), and ICM (MOLLI $474 \pm 93 \mathrm{~ms}$ vs LL $474 \pm 85 \mathrm{~ms}, \mathrm{p}=0.97$ ).

\section{Conclusions}

Pre-contrast MOLLI showed consistently higher T1 values in ICM and HCM patients compared to controls, which implies the potential application of precontrast T1 value in detecting the ICM and HCM. The elevation in T1 might be related to increased myocardial collagen content in HCM patients and impaired myocardial contractility in ICM patients. However, there was no similar $\mathrm{T} 1$ increase demonstrated with LL.

\section{Funding}

This study was supported by Philips Healthcare and Cardiovascular Imaging Laboratory of Cleveland Clinic. 


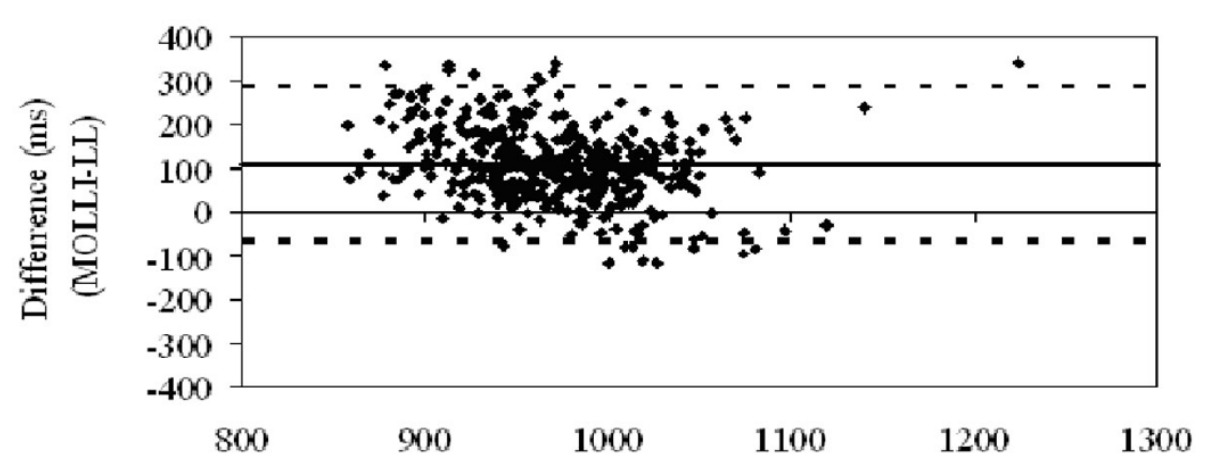

Pre-Contrast Myo cardial T1 (ms)

(MOLLI+LL) $/ 2$

a

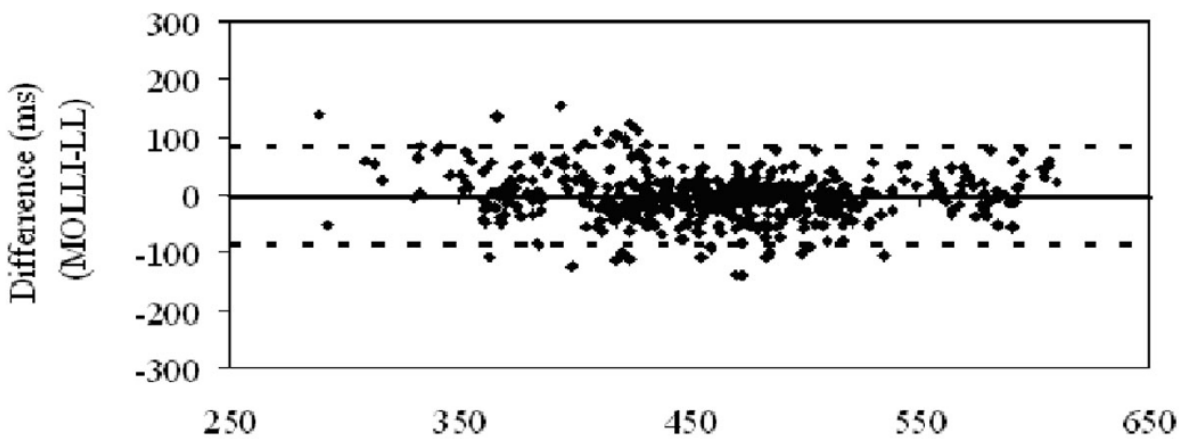

Post-Contrast Myocardial T1 (ms)

$(\mathrm{MOLLI}+\mathrm{LL}) / 2$

Figure 1 Bland-Altman analysis of myocardial T1 MOLLI vs. LL pre- (a) and post-contrast (b) injection in all patient groups.

\section{Author details}

${ }^{1}$ Cleveland Clinic, Cleveland, OH, USA. ${ }^{2}$ Cleveland State University, Cleveland,

$\mathrm{OH}$, USA. ${ }^{3}$ Philips Healthcare, Cleveland, $\mathrm{OH}$, USA.

Published: 30 January 2013

doi:10.1186/1532-429X-15-S1-P78

Cite this article as: Zhou et al: Comparison of look-locker and MOLLI

sequences for $\mathrm{T} 1$ mapping in hypertrophic and ischemic

cardiomyopathy. Journal of Cardiovascular Magnetic Resonance 201315

(Suppl 1):P78.
Submit your next manuscript to BioMed Central and take full advantage of:

- Convenient online submission

- Thorough peer review

- No space constraints or color figure charges

- Immediate publication on acceptance

- Inclusion in PubMed, CAS, Scopus and Google Scholar

- Research which is freely available for redistribution 